\title{
Germinação de Sementes de Capim-Arroz Submetidas a CONDiÇões de LUZ E TEMPERATURA ${ }^{1}$
}

\author{
Germination of Barnyardgrass Seeds under Light and Temperature Conditions
}

BASTIANI, M.O. ${ }^{2}$, LAMEGO, F.P. ${ }^{3}$, NUNES, J.P. ${ }^{2}$, MOURA, D.S. ${ }^{2}$, WICKERT, R.J. ${ }^{2}$ e OLIVEIRA, J.I. ${ }^{2}$

\begin{abstract}
RESUMO - O objetivo deste trabalho foi avaliar os efeitos da temperatura e da luz na germinação de sementes de capim-arroz, em diferentes períodos de armazenamento após a dispersão. O trabalho foi dividido em dois estudos: no primeiro avaliou-se o efeito de três temperaturas $\left(15,25\right.$ e $35^{\circ} \mathrm{C}$ ) e duas condições de luz (presença e ausência) na porcentagem de germinação, comprimento de hipocótilo e comprimento de radícula; e, no segundo, avaliouse o efeito de três temperaturas $\left(15,25\right.$ e $\left.35^{\circ} \mathrm{C}\right)$ no índice de velocidade de germinação e na velocidade de germinação. As sementes foram coletadas em campo logo após o início da dispersão natural. Os estudos foram conduzidos aos 30, 60, 90, 120, 150, 180, 210, 240, 270, 300, 330 e 360 dias após a colheita das sementes. Aos 30 dias após a colheita não houve germinação, independentemente das condições de luz e temperatura. A partir de 60 dias após a colheita, as sementes germinaram tanto na presença quanto na ausência de luz. A ausência de luz promoveu o aumento no comprimento de hipocótilo, independentemente da temperatura. Sob condição de temperatura de $15^{\circ} \mathrm{C}$ e ausência de luz, as sementes apresentaram maior comprimento de radicula. $\mathrm{O}$ incremento da temperatura proporcionou aumento no índice de velocidade de germinação e na velocidade de germinação das sementes. O entendimento dos fatores que afetam a germinação do capim-arroz contribui para o desenvolvimento de práticas de manejo cultural dessa importante espécie daninha que interfere em algumas culturas, incluindo a soja cultivada em rotação com o arroz irrigado.
\end{abstract}

Palavras-chave: Echinochloa crusgalli, teste de germinação, biologia da germinação.

\begin{abstract}
The objective of this research was to evaluate the effects of temperature and light on germination of barnyardgrass in different periods of seed storage after dispersal. The research was divided into two studies: in the first it was evaluated the effect of three temperatures (15, 25 and $35^{\circ} \mathrm{C}$ ) and two light conditions (presence and absence), on germination percentage, hypocotyl length and radicle length; and, in the second, it was evaluated the effect of three temperatures (15, 25 and $35^{\circ} \mathrm{C}$ ) on the germination speed index and germination speed. The seeds were collected in the field shortly after the start of natural seed dispersal. The studies were performed at 30, 60, 90, 120, 150, 180, 210, 240, 270, 300, 330 and 360 days after seed harvest. At 30 days after seed harvest, there was no germination regardless of light conditions and temperature. At 60 days after seed harvest, the seeds germinated both in the presence and absence of light. The absence of light increased hypocotyl length, regardless of temperature. Under $15^{\circ} \mathrm{C}$ temperature condition and absence of light, the seeds showed higher radicle length. The increase in temperature caused an increase on the germination speed index and germination speed of the seeds. The knowledge of factors that affect barnyardgrass germination contribute to develop crop management practices of this important weed that interferes in some crops, including the soybean grown in rotation with rice paddy.
\end{abstract}

Keywords: Echinochloa crusgalli, germination test, germination biology.

1 Recebido para publicação em 3.5.2015 e aprovado em 8.5.2015.

2 Universidade Federal de Pelotas (UFPel), Pelotas-RS, Brasil, <marlon.bastiani@gmail.com>; ${ }^{3}$ Embrapa Pecuária Sul - CPPSul, Bagé-RS, Brasil. 


\section{INTRODUÇÃO}

O capim-arroz (Echinochloa crusgalli var. crusgalli) é uma espécie de ciclo anual, reprodução por sementes, rápido crescimento inicial e elevada demanda por nitrogênio (Kissmann, 2007). A interferência dessa planta daninha tem sido relatada principalmente na cultura do arroz irrigado, além de outros cultivos, como soja e milho (Saccol \& Estefane1, 1995; Galon et al., 2007; Ghanizadeh et al., 2014). Ressalta-se que atualmente tem-se intensificado o uso da cultura da soja como um componente no sistema de rotação de culturas com o arroz irrigado em terras baixas; em contrapartida, infestações de capim-arroz passam a ser importantes para a soja, interferindo na produtividade de grãos quando não manejadas adequadamente.

Em arroz irrigado já foi diagnosticado que a presença de uma planta de capim-arroz por metro quadrado pode ocasionar perdas de até $22 \%$ na produtividade dos grãos, revelando nesse caso que, mesmo após a eliminação de 99\% das plantas dessa espécie na área, na maioria das situações ainda se justificaria a adoção de outras medidas de controle (Galon et al., 2007). O manejo dessa planta daninha normalmente é realizado através do controle químico; por outro lado, o uso intensivo dessa técnica tem favorecido o surgimento de biótipos resistentes a herbicidas.

Atualmente, em diversas culturas, como arroz, milho e soja, já se relatou a resistência do capim-arroz a herbicidas, em muitos casos envolvendo resistência múltipla; por exemplo, em lavouras de arroz nos Estados Unidos, recentemente relatou-se a ocorrência de um biótipo resistente a herbicidas com quatro diferentes mecanismos de ação, incluindo fenoxaprop-ethyl, imazamox, imazethapyr, propanil e quinclorac (Heap, 2015). Nesse sentido, estudos referentes à biologia da espécie, como variáveis relacionadas à germinação, contribuem para o desenvolvimento de estratégias de manejo cultural do capim-arroz, reduzindo assim a dependência exclusiva de herbicidas e a evolução da resistência a eles.
O potencial de germinação da semente e emergência de uma plântula é determinado pela combinação de vários elementos, como temperatura do solo, potencial hídrico, luz, condições gasosas e teor de nitrato (Guillemin et al., 2013). A temperatura é provavelmente o principal fator ambiental que controla a germinação, tanto em culturas quanto em plantas daninhas, atuando diretamente na porcentagem e na taxa de germinação - isso quando outros fatores essenciais para esse processo não estão limitantes no meio (Martinkova et al., 2006).

A dormência de sementes é definida como a incapacidade de sementes intactas e viáveis de germinar quando em condições favoráveis (Bewley, 1997). A temperatura é citada como um dos fatores que podem agir na quebra da dormência da semente, seja ela tanto primária (inata na semente após a maturação na planta-mãe) quanto secundária (induzida após a dispersão das sementes), além de poder induzir a dormência secundária (Taab \& Andersson, 2009). A dormência de sementes caracteriza-se como um fenômeno típico em plantas daninhas anuais, como capim-arroz; para isso, variações sazonais de temperatura no ambiente promovem ciclos de dormência/ não dormência das sementes (Kucewicz et al., 2006; Gardarin \& Colbach, 2015).

A presença de luz também desempenha papel importante nos processos de dormência/ germinação, porém esse efeito é dependente da espécie avaliada. Para sementes de capimarroz em regimes de luz/escuro, ocorreu germinação em torno de 69\%; em contrapartida, na ausência da luz os valores não excederam 24\% (Boyd \& Acker, 2004).

O período de tempo após a dispersão natural das sementes, associado à condição ambiental em que essas sementes se encontram, afeta diretamente a germinação do capim-arroz. Nesse sentido, estudos têm demonstrado que o grau de dormência é relativamente alto por curto período de tempo após a dispersão e que a exposição das sementes tanto à alta quanto à baixa temperatura, nesse período, auxilia na quebra da dormência e aumenta a porcentagem de germinação (Martinkova et al., 2006; Chauhan \& Johnson, 2009). 
A germinação de capim-arroz possui faixa de temperatura adequada e é estimulada na presença de luz, tendo comportamento variável ao longo de um período de armazenamento das sementes após a dispersão. Nesse sentido, o melhor entendimento da biologia da germinação de capim-arroz pode contribuir na elaboração de estratégias para o manejo dessa espécie, pois, tendo o conhecimento dos fatores determinantes da germinação, sobretudo luz e temperatura, torna-se possivel, por exemplo, prever a época mais provável de germinação, bem como auxiliar na escolha do método de controle mais adequado para essa planta daninha.

Dessa forma, objetivou-se com este trabalho avaliar os efeitos da temperatura e da luz na germinação de sementes de capim-arroz, em diferentes períodos de armazenamento após a dispersão.

\section{MATERIAL E MÉTODOS}

O trabalho foi dividido em dois estudos, ambos conduzidos em câmaras de crescimento do tipo BOD no Laboratório de Dinâmica de Herbicidas da UFPel, Capão do LeãoRS, durante o período de junho/2013 a junho/ 2014. As sementes de capim-arroz foram previamente coletadas em campo, no Centro Agropecuário da Palma (latitude 3148'25,4" e longitude $\left.52^{\circ} 28^{\prime} 53,4^{\prime \prime}\right)$, pertencente a UFPel, logo após o início da dispersão natural das sementes, em maio de 2013. Em seguida, elas foram limpas manualmente e armazenadas em embalagens de papel sob condição de temperatura ambiente. Tanto para o Estudo 1 como para o Estudo 2, as sementes foram mantidas em embalagem de papel em sala com temperatura ambiente, ou seja, não foram mantidas em geladeira, até cada período preestabelecido de uso, ou seja, 30, 60, 90, 120, 150, 180, 210, 240, 270, 300, 330 e 360 dias após a colheita das sementes (DAC).

\section{Efeito da temperatura e luz sobre a germinação, o comprimento do hipocótilo e o comprimento da radícula}

Para o Estudo 1, o delineamento experimental utilizado foi o inteiramente casualizado (DIC) com cinco repetições, sendo os tratamentos arranjados em esquema fatorial
$2 \times 3$, em que o fator A foi composto por duas condições de luz (presença e ausência), e o fator $B$, por três niveis de temperatura $(15$, 25 e $35^{\circ} \mathrm{C}$ ). As unidades experimentais constituiram-se de 50 sementes de capimarroz, distribuídas uniformemente em caixa tipo gerbox (com dimensões de $12 \times 12 \times 4 \mathrm{~cm}$ ) contendo duas folhas de papel mata-borrão, previamente umedecidas com água destilada em quantidade equivalente a três vezes o peso do papel, segundo protocolo estabelecido pela RAS (Brasil, 2009). As caixas foram acondicionadas em sacos plásticos para evitar a perda de umidade e, logo após, incubadas em câmara com temperatura constante, de acordo com cada tratamento. No tratamento com a presença de luz utilizou-se fotoperiodo de 12/12 horas (dia/noite), e o tratamento com ausência de luz foi proporcionado pela cobertura total das unidades experimentais com papel-alumínio, de modo a impedir que as sementes recebessem luz.

A porcentagem de germinação foi avaliada aos 14 dias após a semeadura (DAS), considerando como germinadas as sementes que apresentavam $2 \mathrm{~mm}$ de protrusão radicular (Chauhan \& Johnson, 2009). Os comprimentos do hipocótilo e radícula foram mensurados no mesmo momento, utilizando-se uma régua milimetrada, a partir da mensuração de dez plantas por unidade experimental.

Este estudo foi conduzido aos 30, 60, 90, $120,150,180,210,240,270,300,330 \mathrm{e}$ 360 dias após a colheita das sementes (DAC), determinando-se sempre a porcentagem de germinação, o comprimento do hipocótilo e o comprimento da radícula para cada época de condução do estudo.

\section{Efeito da temperatura sobre o indice de velocidade de germinação (IVG) e a velocidade de germinação (VG)}

Para o Estudo 2, o delineamento experimental utilizado foi também inteiramente casualizado com cinco repetições, sendo os tratamentos compostos por três niveis de temperaturas $\left(15,25\right.$ e $\left.35^{\circ} \mathrm{C}\right)$. As unidades experimentais e seu acondicionamento seguiram os mesmos procedimentos apresentados no experimento anterior, exceto que nesse caso não se avaliou o efeito da presença 
ou ausência de luz; para isso, utilizou-se fotoperiodo de 12/12 horas (dia/noite).

Para determinação do IVG e VG, em cada época de condução dos experimentos, efetuaram-se contagens diárias da germinação, sempre no mesmo horário, até totalizar 14 DAS, sendo consideradas germinadas as sementes que apresentavam $2 \mathrm{~mm}$ de protrusão radicular (Chauhan \& Johnson, 2009). Esses valores diários foram computados, sendo o IVG (eq. 1) e VG (eq. 2) calculados através da fórmula proposta por Maguire (1962) e Edmond \& Drapala (1958), respectivamente. $\mathrm{O} \mathrm{G}_{1}, \mathrm{G}_{2}$ e $\mathrm{G}_{\mathrm{n}}$ corresponderam aos números de sementes germinadas na primeira, segunda e última contagem, respectivamente; e $\mathrm{N}_{1}, \mathrm{~N}_{2}$ e $\mathrm{N}_{\mathrm{n}}$ foram os números de dias decorridos até a primeira, segunda e última contagem, respectivamente.

$$
\begin{aligned}
& I V G=\frac{G_{1}}{N_{1}}+\frac{G_{2}}{N_{2}}+\ldots+\frac{G_{n}}{N_{n}} \\
& V G=\frac{\left(N_{1} G_{1}+N_{2} G_{2}+\ldots N_{n} G_{n}\right)}{\left(G_{1}+G_{2}+\ldots+G_{n}\right)}
\end{aligned}
$$

Este estudo foi conduzido aos 30, 60, 90, $120,150,180,210,240,270,300,330$ e 360 DAC, realizando-se avaliações do índice de velocidade de germinação (IVG) e da velocidade de germinação (VG) para cada época de condução, similar ao Estudo 1.

Os dados obtidos nos dois estudos primeiramente foram testados quanto à normalidade pelo teste de Shapiro-Wilk $(\geq 0,05)$; quando necessário, realizou-se a transformação dos dados, procedendo da seguinte forma: os dados de germinação foram transformados por Arco seno $\sqrt{\frac{x}{100}}(60,180,210,240,270,300$, 330 e $360 \mathrm{DAC})$ e $\ln x+1(90,120$ e 150); o comprimento do hipocótilo, transformado por Arco seno $\sqrt{\frac{x}{100}}(60$ e $90 \mathrm{DAC})$; o comprimento da radícula, transformado por $\log (x+1)$ (60 DAC) e $\log (x+0,5)(90 ; 210$ e 270 DAC); o índice de velocidade de germinação, transformado por Arco seno (90, 120, 150, 180, 210 e 360 DAC); e os valores de velocidade de germinação, transformados por $\log (x+0,5)$ (todos períodos de condução dos experimentos). O tipo de transformação escolhido para cada variável foi determinado de acordo com indicação do software estatístico utilizado. Posteriormente, procedeu-se à análise de variância pelo teste $\mathrm{F}(\mathrm{p} \leq 0,05)$; quando significativo, foram realizados testes de médias dos tratamentos, utilizando o teste de Tukey para comparação entre temperaturas e o teste $\mathrm{T}$ para comparação entre regimes de luz, ambos a $5 \%$ de probabilidade $(\mathrm{p} \leq 0,05)$.

\section{RESULTADOS E DISCUSSÃO}

\section{Efeito da temperatura e luz sobre a germinação, o comprimento do hipocótilo e o comprimento da radícula}

Para todas as variáveis testadas, ocorreu interação $(p \leq 0,05)$ entre regimes de luz e temperatura, à exceção do período de $30 \mathrm{DAC}$, no qual não houve germinação de capim-arroz, independentemente da temperatura (Tabela 1). Dessa forma, as variáveis comprimento do hipocótilo e comprimento da radícula não foram mensuradas. Na ausência de luz, aos 60 DAC em temperatura de $35^{\circ} \mathrm{C}$, da mesma forma que na avaliação anterior, não houve germinação; no entanto, para as demais temperaturas aos $60 \mathrm{DAC}$, a porcentagem de germinação foi próxima a zero $(1,2 \%)$ (Tabela 1$)$.

Independentemente da temperatura utilizada, observou-se maior porcentagem de germinação sob condição de luz quando comparada à condição de escuro, salvo para temperatura de $35{ }^{\circ} \mathrm{C}$ aos 90 e 120 DAC (Tabela 1). Quando avaliando a germinação apenas na presença de luz, encontraram-se valores distintos entre temperaturas, principalmente no período de 60 a $180 \mathrm{DAC}$, em que as menores porcentagens foram observadas para as sementes submetidas a $35^{\circ} \mathrm{C}$; em média, as maiores taxas de germinação foram alcançadas na temperatura de $25{ }^{\circ} \mathrm{C}$ (Tabela 1 ). No periodo de 210 até $330 \mathrm{DAC}$, os tratamentos expostos à luz não foram influenciados pela variação de temperatura, ficando acima de $45 \%$. Na ausência de luz, em geral, diferenças entre temperaturas apresentaram-se mais evidentes a partir de $180 \mathrm{DAC}$, quando se observou que as maiores porcentagens de germinação ocorreram quando as sementes foram submetidas à temperatura de $35^{\circ} \mathrm{C}$. 
Tabela 1 - Efeito dos regimes de temperatura e luminosidade sobre a germinação de capim-arroz (Echinochloa crusgalli) em diferentes períodos de dias após a colheita das sementes (DAC), FAEM/UFPel, Capão do Leão-RS, 2013/14

\begin{tabular}{|c|c|c|c|c|c|c|c|}
\hline \multirow{3}{*}{$\begin{array}{l}\text { DAC } \\
\text { (dias) }\end{array}$} & \multicolumn{6}{|c|}{ Germinação (\%) } & \multirow{3}{*}{ CV (\%) } \\
\hline & \multicolumn{3}{|c|}{ Luz } & \multicolumn{3}{|c|}{ Escuro } & \\
\hline & $15^{\circ} \mathrm{C}$ & $25^{\circ} \mathrm{C}$ & $35^{\circ} \mathrm{C}$ & $15^{\circ} \mathrm{C}$ & $25^{\circ} \mathrm{C}$ & $35^{\circ} \mathrm{C}$ & \\
\hline 30 & $0,0 a^{\text {ns }}$ & $0,0 a^{\text {ns }}$ & $0,0 \mathrm{a}^{\mathrm{ns}}$ & $0,0 \mathrm{a}$ & $0,0 \mathrm{a}$ & $0,0 \mathrm{a}$ & 0,0 \\
\hline 60 & $6,4 b^{*}$ & $23,6 a^{*}$ & $1,2 c^{*}$ & $1,2 \mathrm{a}$ & $1,2 \mathrm{a}$ & $0,0 \mathrm{a}$ & 36,0 \\
\hline 90 & 46,0 a* & $81,6 \mathrm{a}^{*}$ & $8,0 b^{\mathrm{ns}}$ & $15,2 \mathrm{a}$ & $24,8 \mathrm{a}$ & $8,4 \mathrm{~b}$ & 11,3 \\
\hline 120 & $64,8 \mathrm{~b}^{*}$ & $91,2 \mathrm{a}^{*}$ & $26,8 c^{\text {ns }}$ & $18,8 \mathrm{~b}$ & $45,0 \mathrm{a}$ & $18,0 \mathrm{~b}$ & 5,9 \\
\hline 150 & $77,6 a^{*}$ & $80,2 a^{*}$ & $44,0 \mathrm{~b}^{*}$ & 26,0 a & $26,4 \mathrm{a}$ & $30,0 \mathrm{a}$ & 7,1 \\
\hline 180 & $82,8 a^{*}$ & $75,6 a^{*}$ & $61,6 b^{*}$ & $17,0 \mathrm{~b}$ & $18,8 \mathrm{~b}$ & $29,2 \mathrm{a}$ & 9,0 \\
\hline 210 & $67,2 a^{*}$ & $70,0 a^{*}$ & $74,0 \mathrm{a}^{*}$ & $10,4 \mathrm{~b}$ & $18,0 \mathrm{~b}$ & $35,2 \mathrm{a}$ & 15,6 \\
\hline 240 & $62,4 a^{*}$ & $66,4 a^{*}$ & $72,8 a^{*}$ & $10,5 \mathrm{~b}$ & $9,2 \mathrm{~b}$ & $36,5 \mathrm{a}$ & 13,5 \\
\hline 270 & $58,8 a^{*}$ & $65,0 \mathrm{a}^{*}$ & $69,2 a^{*}$ & $5,2 \mathrm{~b}$ & $6,4 \mathrm{~b}$ & $39,8 \mathrm{a}$ & 16,1 \\
\hline 300 & $54,0 a^{*}$ & $64,8 a^{*}$ & $65,2 a^{*}$ & $6,0 \mathrm{~b}$ & $6,4 \mathrm{~b}$ & $39,6 \mathrm{a}$ & 15,2 \\
\hline 330 & $45,6 \mathrm{a}^{*}$ & $64,4 a^{*}$ & $62,0 a^{*}$ & $4,4 \mathrm{~b}$ & $9,6 \mathrm{~b}$ & $36,8 \mathrm{a}$ & 15,7 \\
\hline 360 & $42,4 b^{*}$ & 62,8 a* & $56,4 \mathrm{ab}^{*}$ & $2,8 \mathrm{c}$ & $9,1 \mathrm{~b}$ & $34,0 \mathrm{a}$ & 14,9 \\
\hline
\end{tabular}

Médias seguidas de letras iguais nas linhas comparam os regimes de temperatura e não diferem entre si pelo teste de Tukey ( $\mathrm{p} \leq 0,05$ ), dentro de cada condição de luz. * e ns diferem e não diferem, respectivamente, comparando os regimes de luz pelo teste $T$ ( $p \leq 0,05)$, dentro de cada temperatura.

É importante ressaltar os períodos de máxima porcentagem de germinação, para a presença de luz, os quais ocorreram aos 180 $(82,8 \%), 120(91,20 \%)$ e $210(74 \%)$ DAC, nas temperaturas de 15,25 e $35^{\circ} \mathrm{C}$, respectivamente. Na condição de ausência de luz, maiores valores foram alcançados aos 150 (26\%), $120(45 \%)$ e $270(39,8 \%)$ DAC, para 15 , 25 e $35^{\circ} \mathrm{C}$, respectivamente. Se forem considerados apenas esses períodos de máxima porcentagem de germinação, a ausência de luz, para as temperaturas de 15,25 e $35^{\circ} \mathrm{C}$, proporcionou reduções significativas, na ordem de 31, 49 e 54\%, respectivamente, quando comparados aos tratamentos submetidos a exposição à luz (Tabela 1).

A resposta da germinação em função da temperatura pode ser melhor explicada através de um gráfico, o qual geralmente possui "forma de sino", contendo a temperatura basal (temperatura mínima), a temperatura ótima (temperatura em que a germinação é máxima) e a temperatura máxima para germinação (Martinkova et al., 2006). Estudo realizado por Guillemin et al. (2013) constatou que sementes de capim-arroz germinaram entre temperaturas de 8 a $35^{\circ} \mathrm{C}$ e que na faixa de 25 a $30^{\circ} \mathrm{C}$ as porcentagens de germinação mantiveram-se muito próximas; além disso, as temperaturas basal e ótima de germinação foram de 8 e $25{ }^{\circ} \mathrm{C}$, respectivamente. No entanto, os dados encontrados neste estudo sugerem que o efeito da temperatura sobre a germinação de capim-arroz também é variável em função da idade das sementes.

A elevada amplitude dos valores de germinação entre temperaturas encontrada neste estudo pode estar associada ao grau de dormência presente nas sementes, sobretudo nas primeiras épocas de avaliação após a colheita delas. A dormência em sementes é uma característica comum de muitas espécies de plantas daninhas e de grande importância ecológica, destacando-se que a quebra da dormência nas sementes pode ser proporcionada por diversos fatores, principalmente luz, temperatura de incubação, estratificação por frio e nitrogênio (Tang et al., 2008).

Em um período de 30 dias após a colheita de sementes dispersas diretamente da plantamãe no campo, não houve germinação do capim-arroz, independentemente das condições de luz e temperatura (Tabela 1), o que reforça a hipótese da ocorrência de dormência. Ademais, ocorreu aumento na porcentagem de germinação paralelamente ao aumento da idade das sementes, até expressar um 
potencial máximo de germinação; o período necessário para esse processo foi variável em função da temperatura.

Existe um determinado período de tempo, logo após a dispersão natural, em que as sementes se encontram em estado de dormência. À medida que se perde essa característica, algumas espécies de plantas daninhas têm como estratégia ecológica, primeiramente, germinar em uma faixa restrita de temperatura; posteriormente, com o aumento da idade das sementes, elas apresentam a capacidade de germinar sob uma faixa mais ampla de temperatura (Martinkova et al., 2006).

Os resultados permitem sugerir que as sementes de capim-arroz são estimuladas na presença de luz, porém a luz não é considerada um fator limitante para o processo de germinação. Sementes de muitas espécies de plantas daninhas podem germinar apenas na presença de luz, enquanto outras germinam igualmente em condições de presença e ausência de luz (Opeña et al., 2014). Alguns estudos já constataram comportamento similar com espécies de Echinochloa colona, E. crusgalli e E. glabrescens, o que corrobora os resultados encontrados no presente estudo
(Boyd \& Acker, 2004; Chauhan \& Johnson, 2011; Opeña et al., 2014).

Independentemente do periodo após a colheita das sementes e da temperatura, a ausência total de luz promove maior comprimento no hipocótilo de capim-arroz, quando comparada aos regimes de luz (Tabela 2). Quando avaliado o efeito das temperaturas na presença de luz, observou-se que sementes submetidas à condição de temperatura de $35{ }^{\circ} \mathrm{C}$ apresentaram, em média, maior comprimento do hipocótilo, seguida pelas temperaturas de 25 e $15^{\circ} \mathrm{C}$, em ordem decrescente, respectivamente. Entretanto, na ausência de luz, independentemente da idade das sementes, o maior comprimento da parte aérea foi observado para a temperatura de $25^{\circ} \mathrm{C}$, seguida de 35 e $15^{\circ} \mathrm{C}$, em ordem decrescente, respectivamente.

Quando as sementes germinam nas condições de escuro, ocorre maior investimento das reservas das sementes para o alongamento da parte aérea, com a finalidade de interceptação da luz, a fim de começar a atividade fotossintética; contudo, esse maior investimento também atua como um dreno, limitando o crescimento das raízes (Taiz \& Zeiger, 2013).

Tabela 2 - Efeito dos regimes de temperatura e luminosidade sobre o comprimento do hipocótilo de capim-arroz (Echinochloa crusgalli) em diferentes períodos de dias após a colheita das sementes (DAC), FAEM/UFPel, Capão do Leão-RS, 2013/14

\begin{tabular}{|c|c|c|c|c|c|c|c|}
\hline \multirow{3}{*}{$\begin{array}{l}\text { DAC } \\
\text { (dias) }\end{array}$} & \multicolumn{6}{|c|}{ Comprimento do hipocótilo (cm) } & \multirow{3}{*}{$\mathrm{CV}(\%)$} \\
\hline & \multicolumn{3}{|c|}{ Luz } & \multicolumn{3}{|c|}{ Escuro } & \\
\hline & $15^{\circ} \mathrm{C}$ & $25^{\circ} \mathrm{C}$ & $35^{\circ} \mathrm{C}$ & $15^{\circ} \mathrm{C}$ & $25^{\circ} \mathrm{C}$ & $35^{\circ} \mathrm{C}$ & \\
\hline 30 & - & - & - & - & - & - & - \\
\hline 60 & $0,51 b^{\text {ns }}$ & $2,92 a^{*}$ & $0,42 \mathrm{~B}^{*}$ & $0,33 \mathrm{~b}$ & $0,61 \mathrm{a}$ & $0,00 \mathrm{c}$ & 12,49 \\
\hline 90 & $0,68 b^{*}$ & $2,55 a^{*}$ & $2,14 \mathrm{a}^{\mathrm{ns}}$ & $1,48 \mathrm{c}$ & $5,51 \mathrm{a}$ & $2,98 \mathrm{~b}$ & 14,44 \\
\hline 120 & $1,25 \mathrm{c}^{*}$ & $2,99 \mathrm{~b}^{*}$ & $4,54 \mathrm{a}^{\mathrm{ns}}$ & $2,81 \mathrm{~b}$ & $5,66 \mathrm{a}$ & $5,85 \mathrm{a}$ & 20,67 \\
\hline 150 & $1,09 \mathrm{~b}^{*}$ & $4,43 a^{*}$ & $4,60 \mathrm{~A}^{*}$ & $3,44 \mathrm{~b}$ & $7,80 \mathrm{a}$ & $6,69 \mathrm{a}$ & 14,06 \\
\hline 180 & $1,39 \mathrm{~b}^{*}$ & $4,16 a^{*}$ & $3,85 \mathrm{~A}^{*}$ & $3,16 \mathrm{c}$ & $7,61 \mathrm{a}$ & $5,99 \mathrm{~b}$ & 11,01 \\
\hline 210 & $1,17 c^{*}$ & $3,74 b^{*}$ & $5,91 A^{*}$ & $4,45 \mathrm{c}$ & $8,02 \mathrm{a}$ & $6,79 \mathrm{~b}$ & 12,57 \\
\hline 240 & $0,98 b^{*}$ & $3,12 a^{*}$ & $3,59 A^{*}$ & $2,85 \mathrm{~b}$ & $6,93 \mathrm{a}$ & $6,36 \mathrm{a}$ & 18,17 \\
\hline 270 & $0,90 \mathrm{~b}^{*}$ & $3,32 a^{*}$ & $3,69 A^{*}$ & $3,73 \mathrm{~b}$ & 6,59 a & 5,96 a & 15,42 \\
\hline 300 & $1,17 c^{*}$ & $2,80 \mathrm{~b}^{*}$ & $3,55 A^{*}$ & $3,76 \mathrm{~b}$ & $5,96 \mathrm{a}$ & $5,48 \mathrm{a}$ & 18,66 \\
\hline 330 & $1,72 b^{*}$ & $3,63 a^{*}$ & $4,26 a^{\text {ns }}$ & $5,78 \mathrm{a}$ & $6,89 \mathrm{a}$ & $5,54 \mathrm{a}$ & 21,99 \\
\hline 360 & $0,84 c^{*}$ & $3,60 b^{*}$ & $4,30 \mathrm{a}^{\mathrm{ns}}$ & $2,21 \mathrm{~b}$ & $5,64 \mathrm{a}$ & $5,25 \mathrm{a}$ & 22,06 \\
\hline
\end{tabular}

Médias seguidas de letras iguais nas linhas comparam os regimes de temperatura e não diferem entre si pelo teste de Tukey ( $\leq \leq 0,05)$, dentro de cada condição de luz. * e ${ }^{\text {ns }}$ diferem e não diferem, respectivamente, comparando os regimes de luz pelo teste $\mathrm{T}(\mathrm{p} \leq 0,05)$, dentro de cada temperatura. - Não houve germinação. 
As sementes de capim-arroz incubadas sob ausência de luz apresentaram, em média, maior comprimento da radícula em relação à condição de luz, sendo esse efeito notável apenas em baixas temperaturas $\left(15^{\circ} \mathrm{C}\right)$, à exceção do período entre 210 e 300 DAC (Tabela 3 ). Nas temperaturas mais altas $\left(25\right.$ e $\left.35^{\circ} \mathrm{C}\right)$, em geral, não se observaram efeitos da luz sobre o comprimento da radícula (Tabela 3).

Quando comparadas apenas as temperaturas, em geral, nos diferentes períodos de avaliação constatou-se que o comprimento da radicula apresentou maior crescimento na temperatura de $25^{\circ} \mathrm{C}$, para as duas condições de luz avaliadas (presença e ausência).

Venske et al. (2013) observaram, tanto para cultivares de arroz irrigado quanto para biótipos de arroz-vermelho, maiores valores de comprimento de radícula no escuro quando comparadas aos regimes de luz, sendo esse comportamento mais notável em baixas temperaturas $\left(18 / 13^{\circ} \mathrm{C}\right)$. Esses autores destacam que plântulas com esse comportamento têm seu desenvolvimento afetado em condições de frio e ausência de luz, pelo fato de priorizarem o investimento das reservas da semente para o crescimento da raiz, podendo haver falta de reservas para o crescimento da parte aérea.

\section{Efeito da temperatura sobre o indice de velocidade de germinação (IVG) e a velocidade de germinação (VG)}

O IVG foi afetado pela variação na temperatura em todos os períodos testados, exceto aos 30 DAC, em que não foi possível o cálculo da variável devido à ausência de germinação das sementes de capim-arroz (Tabela 4).

Sob a temperatura de $25^{\circ} \mathrm{C}$ dentro do período de 60-150 DAC, as sementes de capimarroz apresentaram altos valores de IVG, em comparação com as demais temperaturas. No entanto, nas avaliações realizadas aos 180 e 210 DAC, essa variável foi semelhante para as temperaturas de 25 e $35^{\circ} \mathrm{C}$. A partir dos 240 DAC observou-se que, quanto maiores as temperaturas de incubação, maiores foram os valores do IVG (Tabela 4).

Da mesma forma, a variável VG foi afetada pelos regimes de temperaturas em todas as épocas de avaliação, exceto aos 30 e 60 DAC (Tabela 5). Destaca-se que, conhecendo-se a variável velocidade de germinação (VG), é

Tabela 3 - Efeito dos regimes de temperatura e luminosidade sobre o comprimento da radícula de capim-arroz (Echinochloa crusgalli) em diferentes períodos de dias após a colheita das sementes (DAC), FAEM/UFPel, Capão do Leão-RS, 2013/14

\begin{tabular}{|c|c|c|c|c|c|c|c|}
\hline \multirow{3}{*}{$\begin{array}{l}\text { DAC } \\
\text { (dias) }\end{array}$} & \multicolumn{6}{|c|}{ Comprimento da radícula $(\mathrm{cm})$} & \multirow{3}{*}{$\mathrm{CV}(\%)$} \\
\hline & \multicolumn{3}{|c|}{ Luz } & \multicolumn{3}{|c|}{ Escuro } & \\
\hline & $15^{\circ} \mathrm{C}$ & $25^{\circ} \mathrm{C}$ & $35^{\circ} \mathrm{C}$ & $15^{\circ} \mathrm{C}$ & $25^{\circ} \mathrm{C}$ & $35^{\circ} \mathrm{C}$ & \\
\hline 30 & - & - & - & - & - & - & - \\
\hline 60 & $0,28 b^{*}$ & $3,86 a^{*}$ & $0,28 b^{*}$ & $0,10 \mathrm{a}$ & $0,20 \mathrm{a}$ & $0,00 \mathrm{a}$ & 33,93 \\
\hline 90 & $1,47 b^{*}$ & $5,45 a^{\text {ns }}$ & $2,17 b^{\mathrm{ns}}$ & $1,56 \mathrm{~b}$ & $4,87 \mathrm{a}$ & $1,93 \mathrm{~b}$ & 25,44 \\
\hline 120 & $1,98 b^{*}$ & $4,16 a^{\text {ns }}$ & $4,89 a^{*}$ & $2,67 \mathrm{~b}$ & 4,86 a & $3,11 \mathrm{~b}$ & 18,41 \\
\hline 150 & $2,15 b^{*}$ & $4,31 \mathrm{a}^{\mathrm{ns}}$ & $3,95 a^{\mathrm{ns}}$ & $3,15 b$ & $4,38 \mathrm{a}$ & $4,08 \mathrm{a}$ & 16,20 \\
\hline 180 & $2,33 c^{*}$ & $5,90 a^{*}$ & $4,16 b^{\text {ns }}$ & $3,28 \mathrm{~b}$ & $4,08 \mathrm{ab}$ & $4,56 \mathrm{a}$ & 13,37 \\
\hline 210 & $3,09 c^{\mathrm{ns}}$ & $6,15 a^{\text {ns }}$ & $4,10 b^{\mathrm{ns}}$ & $3,44 \mathrm{~b}$ & $5,30 \mathrm{a}$ & $3,81 \mathrm{~b}$ & 8,12 \\
\hline 240 & $2,92 b^{\mathrm{ns}}$ & $5,47 a^{\mathrm{ns}}$ & $5,00 a^{*}$ & $2,94 \mathrm{a}$ & $4,12 \mathrm{a}$ & $4,00 \mathrm{a}$ & 19,50 \\
\hline 270 & $3,41 c^{\mathrm{ns}}$ & $5,83 a^{\text {ns }}$ & $4,23 b^{*}$ & $3,01 \mathrm{~b}$ & $5,03 \mathrm{a}$ & $2,58 \mathrm{~b}$ & 7,45 \\
\hline 300 & $3,03 b^{\text {ns }}$ & $4,92 a^{\mathrm{ns}}$ & $4,02 \mathrm{ab}^{\mathrm{ns}}$ & $2,68 \mathrm{a}$ & $4,07 \mathrm{a}$ & $2,60 \mathrm{a}$ & 25,71 \\
\hline 330 & $2,68 b^{*}$ & $4,80 a^{\mathrm{ns}}$ & $2,71 b^{\mathrm{ns}}$ & $3,56 \mathrm{~b}$ & 4,33 ab & $2,50 \mathrm{a}$ & 22,60 \\
\hline 360 & $1,58 b^{*}$ & $5,22 a^{\text {ns }}$ & $4,58 a^{*}$ & $2,84 \mathrm{~b}$ & $5,02 \mathrm{a}$ & $3,19 \mathrm{~b}$ & 18,59 \\
\hline
\end{tabular}

Médias seguidas de letras iguais nas linhas comparam os regimes de temperatura e não diferem entre si pelo teste de Tukey ( $\leq \leq 0,05)$, dentro de cada condição de luz. ${ }^{*}$ e ${ }^{\text {ns }}$ diferem e não diferem, respectivamente, comparando os regimes de luz pelo teste $\mathrm{T}$ ( $\left.\mathrm{p} \leq 0,05\right)$, dentro de cada temperatura. - Não houve germinação. 
Tabela 4 - Efeito dos regimes de temperatura sobre o índice de velocidade de germinação (IVG) de capim-arroz (Echinochloa crusgalli) em diferentes períodos de dias após a colheita das sementes (DAC), FAEM/UFPel, Capão do Leão-RS, 2013/14

\begin{tabular}{|c|c|c|c|c|}
\hline \multirow{2}{*}{$\begin{array}{c}\text { DAC } \\
\text { (dias) }\end{array}$} & \multicolumn{3}{|c|}{ IVG } & \multirow{2}{*}{ CV (\%) } \\
\cline { 2 - 4 } & $15^{\circ} \mathrm{C}$ & $25^{\circ} \mathrm{C}$ & $35^{\circ} \mathrm{C}$ & \\
\hline 30 & - & - & - & - \\
\hline 60 & $0,56 \mathrm{~b}$ & $1,45 \mathrm{a}$ & $0,14 \mathrm{~b}$ & 43,13 \\
\hline 90 & $2,67 \mathrm{~b}$ & $10,87 \mathrm{a}$ & $0,68 \mathrm{c}$ & 8,12 \\
\hline 120 & $4,44 \mathrm{~b}$ & $11,51 \mathrm{a}$ & $4,24 \mathrm{~b}$ & 6,40 \\
\hline 150 & $4,56 \mathrm{c}$ & $13,19 \mathrm{a}$ & $10,39 \mathrm{~b}$ & 8,23 \\
\hline 180 & $5,56 \mathrm{~b}$ & $15,11 \mathrm{a}$ & $13,64 \mathrm{a}$ & 14,07 \\
\hline 210 & $4,25 \mathrm{~b}$ & $13,47 \mathrm{a}$ & $15,59 \mathrm{a}$ & 16,06 \\
\hline 240 & $3,76 \mathrm{c}$ & $11,64 \mathrm{~b}$ & $15,83 \mathrm{a}$ & 12,21 \\
\hline 270 & $3,99 \mathrm{c}$ & $11,68 \mathrm{~b}$ & $16,01 \mathrm{a}$ & 13,53 \\
\hline 300 & $2,86 \mathrm{c}$ & $11,33 \mathrm{~b}$ & $19,33 \mathrm{a}$ & 11,31 \\
\hline 330 & $2,90 \mathrm{c}$ & $11,25 \mathrm{~b}$ & $15,46 \mathrm{a}$ & 19,13 \\
\hline 360 & $2,87 \mathrm{c}$ & $9,44 \mathrm{~b}$ & $15,03 \mathrm{a}$ & 5,78 \\
\hline
\end{tabular}

Médias seguidas de letras iguais nas linhas não diferem entre si pelo teste de Tukey $(\mathrm{p} \leq 0,05)$. - Não houve germinação.

possivel determinar o número de dias que as sementes necessitam para germinar. Neste estudo, os dados de VG mostraram que, quanto menor a temperatura de incubação, maior é o número de dias requeridos para que ocorra germinação em capim-arroz. Em algumas épocas de condução não houve diferenças entre as temperaturas de 25 e $35^{\circ} \mathrm{C}$, porém o VG para a temperatura de $15^{\circ} \mathrm{C}$ sempre apresentou valor mais elevado, ou seja, mais dias foram necessários para a germinação dessas sementes nesta temperatura, quando comparada às demais (Tabela 5).

Estudo avaliando o índice de velocidade de germinação de algumas plantas daninhas mostrou que as espécies Alternathera tenella e Conyza bonariensis não foram afetadas pela variação nos regimes de temperatura testados $\left(15 / 25,20 / 30\right.$ e $20 / 35{ }^{\circ} \mathrm{C}$ de fotoperiodo diurno/noturno), mas, para a espécie Digitaria ciliaris, os máximos valores de IVG foram obtidos quando expostos a flutuações de temperaturas entre $20 / 30$ e $25 / 30{ }^{\circ} \mathrm{C}$ (Vivian et al., 2008). As sementes sob condições de baixas temperaturas reduzem as taxas metabólicas e, consequentemente, a expressão de enzimas responsáveis pelo início do processo germinativo (Mertz et al., 2009).
Existe uma faixa de temperatura ótima em que a taxa de germinação é máxima, porém essa faixa nem sempre é mesma em que ocorre a máxima porcentagem de germinação, conforme se veerificou neste estudo quando se confrontaram essas variáveis. Vleeshouwers (1998) observou que o pico de máxima germinação de Polygonum persicaria ocorreu na temperatura de $25{ }^{\circ} \mathrm{C}$, enquanto a taxa de germinação aumentou linearmente com o incremento da temperatura até $30^{\circ} \mathrm{C}$.

Embora não haja diferenças entre temperaturas na porcentagem de germinação, conforme mostrado no estudo anterior para os períodos de 210-330 DAC (Tabela 1), nota-se que parâmetros relacionados com a germinação de capim-arroz foram influenciados pelos regimes de temperatura e podem assumir grande importância para a elaboração de práticas de manejo. De posse do conhecimento dessas variáveis, presume-se que a planta daninha pode emergir precocemente dentro do ciclo das culturas de verão quando estimuladas por temperaturas mais altas $\left(>25^{\circ} \mathrm{C}\right)$ e que a semeadura precoce da cultura em épocas com temperaturas mais amenas $\left(<25^{\circ} \mathrm{C}\right)$ pode ser uma ferramenta no controle cultural, pelo fato de ela, além de apresentar menor porcentagem de germinação nessa

Tabela 5 - Efeito dos regimes de temperatura sobre a velocidade de germinação (VG) do capim-arroz (Echinochloa crusgalli) em diferentes períodos de dias após a colheita das sementes (DAC), FAEM/UFPel, Capão do Leão-RS, 2013/14

\begin{tabular}{|c|c|c|c|c|}
\hline \multirow{2}{*}{$\begin{array}{c}\text { DAC } \\
\text { (dias) }\end{array}$} & \multicolumn{3}{|c|}{ VG (dias) } & \multirow{2}{*}{ CV (\%) } \\
\cline { 2 - 4 } & $15{ }^{\circ} \mathrm{C}$ & $25^{\circ} \mathrm{C}$ & $35^{\circ} \mathrm{C}$ & \\
\hline 30 & - & - & - & - \\
\hline 60 & $12,24 \mathrm{a}$ & $8,12 \mathrm{a}$ & $7,20 \mathrm{a}$ & 51,63 \\
\hline 90 & $11,10 \mathrm{a}$ & $4,38 \mathrm{~b}$ & $4,54 \mathrm{~b}$ & 9,95 \\
\hline 120 & $9,22 \mathrm{a}$ & $3,91 \mathrm{~b}$ & $3,34 \mathrm{~b}$ & 5,77 \\
\hline 150 & $8,91 \mathrm{a}$ & $3,52 \mathrm{~b}$ & $2,50 \mathrm{c}$ & 4,15 \\
\hline 180 & $8,62 \mathrm{a}$ & $2,80 \mathrm{~b}$ & $2,88 \mathrm{~b}$ & 3,46 \\
\hline 210 & $8,99 \mathrm{a}$ & $2,85 \mathrm{~b}$ & $2,52 \mathrm{c}$ & 3,37 \\
\hline 240 & $9,37 \mathrm{a}$ & $3,45 \mathrm{~b}$ & $3,21 \mathrm{~b}$ & 5,11 \\
\hline 270 & $8,38 \mathrm{a}$ & $3,02 \mathrm{~b}$ & $2,26 \mathrm{c}$ & 4,79 \\
\hline 300 & $8,88 \mathrm{a}$ & $3,33 \mathrm{~b}$ & $3,09 \mathrm{~b}$ & 4,32 \\
\hline 330 & $9,35 \mathrm{a}$ & $4,01 \mathrm{~b}$ & $2,22 \mathrm{c}$ & 2,76 \\
\hline 360 & $9,02 \mathrm{a}$ & $4,94 \mathrm{~b}$ & $2,30 \mathrm{c}$ & 3,44 \\
\hline
\end{tabular}

Médias seguidas de letras iguais nas linhas não diferem entre si pelo teste de Tukey $(\mathrm{p} \leq 0,05)$. - Não houve germinação. 
condição, também necessitar de mais dias para que esse processo ocorra; consequentemente, a cultura passa a ter vantagem competitiva sobre o capim-arroz. Partindo desse pressuposto, para a cultura da soja semeada em áreas com infestações de capimarroz, destaca-se a importância de realizar a semeadura da cultura até meados de novembro, pois nesse período espera-se que a temperatura média do solo ainda se encontre abaixo das condições ideais para a germinação do capim-arroz. Entretanto, mesmo que a porcentagem de germinação da planta daninha seja menor no período citado, ainda assim pode causar prejuízos para a cultura, fazendo-se necessária a adoção de outras medidas de controle do capim-arroz, como parte do manejo integrado de plantas daninhas.

Diante dos resultados obtidos, conclui-se que a germinação de sementes de capim-arroz é afetada por variações nos regimes de luz e temperatura, tendo respostas variáveis em função da idade das sementes. O capim-arroz pode germinar tanto na presença quanto na ausência de luz, embora nessa última sejam observadas menores porcentagens de germinação. O crescimento do hipocótilo e o da radícula são prejudicados pela ausência de luz e menores temperaturas. Além disso, baixas temperaturas diminuem a taxa de germinação e, consequentemente, aumentam o número de dias necessários para que a germinação ocorra. Por fim, ressalta-se a importância do entendimento dos fatores que afetam a germinação do capim-arroz, no intuito de ajudar no desenvolvimento de práticas de manejo cultural dessa importante planta daninha, que pode competir com a soja cultivada em rotação com o arroz irrigado.

\section{AGRADECIMENTOS}

À Capes, ao CNPq e à Fapergs, pelas bolsas de iniciação científica e de mestrado.

\section{LITERATURA CITADA}

BEWLEY, D. J. Seed germination and dormancy. Plant Cell, v. 9, n. 7, p. 1055-1066, 1997.

BOYD, N.; ACKER, R. V. Seed germination of common weed species as affected by oxygen concentration, light, and osmotic potential. Weed Sci., v. 52, n. 4, p. 589-596, 2004.
BRASIL. Ministério da Agricultura, Pecuária e

Abastecimento. Regras para análise de sementes. Brasília: 2009. 395 p.

CHAUHAN, B. S.; JOHNSON, D. E. Seed germination ecology of junglerice (Echinochloa colona): a major weed of rice. Weed Sci., v. 57, n. 3, p. 235-240, 2009.

CHAUHAN, B. S.; JOHNSON, D. E. Ecological studies on Echinochloa crus-galli and the implications for weed management in direct-seeded rice. Crop Protec., v. 30, n. 11, p. 1385-1391, 2011.

EDMOND, J. B.; DRAPALA, W. J. The effects of temperature, sand and soil, and acetone on germination of okra seed. Proc. Am. Soc. Hortic. Sci., v. 71, n. 2, p. 428-434, 1958.

GALON, L. et al. Estimativa das perdas de produtividade de grãos em cultivares de arroz (Oryza sativa) pela interferência do capim-arroz (Echinochloa spp.). Planta Daninha, v. 25, n. 4, p. 697-707, 2007.

GARDARIN, A.; COLBACH, N. How much of seed dormancy in weeds can be related to seed traits?. Weed Res., v. 55, n. 1, p. 14-25, 2015.

GHANIZADEH, H. et al. Effect of weed interference on Zea mays: growth analysis. Weed Biol. Manag., v. 14, n. 2, p. 133-137, 2014.

GUILLEMIN, J.P. et al. Assessing potential germination period of weeds with base temperatures and base water potentials. Weed Res., v. 53, n. 1, p. 76-87, 2013.

HEAP, I. International survey of herbicide resistant weeds. Disponível em: <http://www.weed science.org>. Acesso em: 14 mar. 2015.

KISSMANN, K. G. Plantas infestantes e nocivas. 3.ed. São Paulo: Basf, 2007. Tomo I. CD-ROM.

KUCEWICZ, M. Ecophysiological conditions of germination of barnyardgrass [Echinochloa crus-galli (L.) p. beauv.]

diaspores. J. Plant Protec. Res., v. 46, n. 1, p. 73-84, 2006.

MAGUIRE, J. D. Speed of germination-aid in selection and evaluation for seedling emergence and vigor. Crop Sci., v. 2, n. 1, p. 176-177, 1962.

MARTINKOVA, Z. et al. Seed age and storage conditions influence germination of barnyardgrass (Echinochloa crusgalli). Weed Sci., v. 54, n. 2, p. 298-304, 2006.

MERTZ, L. C. et al. Alterações fisiológicas em sementes de arroz expostas ao frio na fase de germinação. R. Bras.

Sementes, v. 31, n. 2, p. 254-262, 2009. 
OPEÑA, J. L. et al. Seed germination ecology of Echinochloa glabrescens and its implication for management in rice (Oriza sativa L.). Plos one, v. 9, n. 3, p. 1-13, 2014.

SACCOL, V. A.; ESTEFANEL, V. Competição entre o capimarroz e a soja cultivada em solo hidromórfico: II Efeito sobre algumas características agronômicas da soja. Pesq. Agropec. Bras., v. 30, n. 3, p. 327-338, 1995.

TAAB, A.; ANDERSSON, L. Seed dormancy dynamics and germination characteristics of Solanum nigrum. Weed Res., v. 49, n. 5, p. 490-498, 2009.

TAIZ, L.; ZEIGER, E. Fisiologia vegetal. 5.ed. Porto Alegre: Armed, 2013. 918 p.
TANG, D. S. et al. Role of red light, temperature, stratification and nitrogen in breaking seed dormancy of Chenopodium album L. J. Crop Sci. Biotechnol., v. 11, n. 3, p. 199-204, 2008.

VENSKE, E. et al. Initial development of red and cultivated rice in response to light and air temperature. J. Seed Sci., v. 35, n. 4, p. 510-518, 2013.

VIVIAN, R. et al. Efeito da luz e da temperatura na germinação de Alternathera tenella, Conyza bonariensis e Digitaria ciliaris. Planta Daninha, v. 26, n. 3, p. 507-513, 2008.

VLEESHOUWERS, L. M. The effect of seed dormancy on percentage and rate of germination in Polygonum persicaria, and its relevance for crop-weed interaction. Ann. Appl. Biol., v. 132, n. 2, p. 289-299, 1998. 